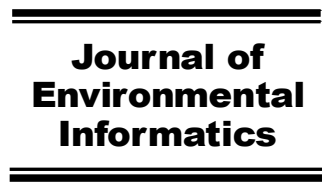

Www.iseis.org/jei

\title{
Improvement of Envisat Altimetric Measurements in Taiwan Coastal Oceans by a Developed Waveform Retracking System
}

\author{
C. Y. Kuo*, T. Y. Yang, H. C. Kao, C. K. Wang, W. H. Lan, and H. Z. Tseng \\ Department of Geomatics, National Cheng Kung University, Tainan 70101, Taiwan
}

Received 21 April 2015; revised 27 July 2015; accepted 2 September 2015; published online 7 December 2015

\begin{abstract}
A new waveform retracking system applied on 18-Hz Envisat RA-2 data (cycles 10 to 90) was successfully developed in this study and aimed to improve the accuracy of measuring sea surface heights (SSHs) in coastal oceans around Taiwan. The specialized retracking system comprised the CurveFit retracker of fitting altimetry subwaveforms to the Brown model along with Gaussian peak models and a technique of removing non-ocean waveforms. Therefore, our system can favorably retain ocean-reflected waveforms and effectively reduce the land contamination in reflected waveforms. Results demonstrated that the CurveFit retracker performed best within 0 to $5 \mathrm{~km}$ offshore in all the study areas, with improvement percentages (IMPs) reaching a maximum of $92 \%$. Within 5 to $10 \mathrm{~km}$ from the coast, the CurveFit retracked SSHs considerably improved with an IMP of up to 93\%. Given that most waveforms, particularly of ground tracks from ocean to land, conformed to a typical ocean model in the 5 to $10 \mathrm{~km}$ zone, all the used retrackers similarly achieved satisfactory and equivalent improvements. This study also manifested that the accuracy of retracked SSHs largely depends on both land topography and ground tracks approaching or leaving land. The amount and accuracy of valid retracked measurements along ground tracks from land to ocean were remarkably lower than those of ground tracks across the coastline reversely. Moreover, the altimetric waveforms were highly contaminated by coastal land topography when ground tracks approached coastal flat land from the ocean or passed through coastal undulating topography toward the ocean.
\end{abstract}

Keywords: satellite altimetry, waveform retracking, coastal ocean, land topography, ground track

\section{Introduction}

Increase in global sea level substantially affects the economy and human societal well-being and could induce vulnerability in coastal regions that are the most populated and highly economically developed areas worldwide (Nicholls, 2011). Nicholls and Leatherman (1994) summarized the effects, including inundation of low-lying areas, erosion of beaches and bluffs, salt intrusion into aquifers and surface waters, higher water tables, and increased flooding and storm surge damage that severely harm people's lives and properties. For example, salt intrusion could affect water quality, water ecosystems and water resources management resulting in water supply shortage (Xia et al., 2015; Rahmani and Zarghami, 2015). To prevent property damage or loss of life, the primary tasks are as follows: to closely and accurately monitor coastal oceans, forecast coastal disasters, and take precautions against disasters. Among these tasks, the exact measurement of variations in coastal sea level is primarily for disaster prevention. Traditionally, long-term tide gauge records are dedicated to

${ }^{*}$ Corresponding author. Tel.: +886-6-275-7575 (ext. 63826); fax: +886-6237-5764. E-mail address: kuo70@mail.ncku.edu.tw (C. Y. Kuo).

ISSN: 1726-2135 print/1684-8799 online

(C) 2018 ISEIS All rights reserved. doi: 10.3808/jei.201500324 measure local sea level changes. However, some disadvantages exist in monitoring coastal sea level change using gauges, including uneven and non-global distribution of gauge stations, vertical land motions, tide gauge benchmark jumps, and the incompleteness of gauge records such as large data gaps, and unequal record lengths. In recent years, satellite altimetry has been developed to map global sea surface heights (SSHs) with unprecedented spatiotemporal resolution and accuracy, which can supplement traditionnal tide gauges to obtain long-term and accurate coastal sea level variations (e.g., Willis et al., 2010).

With the emergence of global warming, monitoring and understanding coastal regions have become important recently; thus, researchers have been focusing on assessing flooding risks, coastal erosion, and pollutant areas using coastal altimetry measurements (COASTALT, 2011; Vignudelli et al., 2011). The observation principle of satellite altimetry is to measure the round-trip travel times of transmitted radar pulses between the satellite receiving antenna and the instantaneous ocean surface for calculating ranges from the satellite to ocean surfaces. Nevertheless, some difficulties that require resolution still exist in coastal altimetry applications because of inaccurate measurements caused by complex waveforms reflected from land-sea transition zones (non-ocean surfaces) and low accurate geophysical corrections. Complex waveforms, echoed from oceans within $22 \mathrm{~km}$ from the coast (Deng et al., 
2002), do not conform to the Brown ocean model (Brown, 1977) because of rough topography and inland water near the coastline; thus, the midpoint of the leading edge in waveforms cannot be simply represented as the default gate or be accurately estimated, and then the range between a satellite and the ocean is inaccurate (Deng et al., 2002). To improve the accuracy and quantity of valid altimetric measurements in coastal oceans, various waveform retracking techniques or retracking systems have been developed to reduce the problem caused by complex waveforms. A complete review of waveform retracking methods can be found in the studies of Lee et al. (2008) and Gommenginger et al. (2009; 2011). A coastal waveform retracking system, which systematically analyzes ERS-2 altimeter waveforms around Australia and retracks waveforms depending on waveform characteristics, has been developed by Deng and Featherstone (2006) to successfully improve SSHs within 0 to $5 \mathrm{~km}$ from the coast. However, standard deviations (STDs) of differences between retracked ERS-2 SSHs and AUSGeoid98 geoid heights are still at the meter level.

Researchers have also improved coastal SSHs by modifying waveforms before applying waveform retracking. Idris and Deng (2012) have extracted subwaveforms echoed only from ocean surfaces based on Jason-1 and Jason-2 full waveforms in the Great Barrier Reef, and then retracked subwaveforms using the Brown ocean model to retrieve SSHs. The effective retracked SSHs can reach 2 to $6 \mathrm{~km}$ from the coast for Jason-1 and 1 to $7 \mathrm{~km}$ from the coast for Jason-2 with STDs of 135.99 and $82.82 \mathrm{~cm}$, respectively. Yang et al. (2012) developed the OceanCS retracking strategy, which extracted subwaveforms from Jason-1 coastal-like waveforms according to the ocean return signal and then retracked the subwaveforms using a combination of OCEAN with Offset Center of Gravity (OCOG) retrackers. Tseng et al. (2014) have modified Jason-2 and Envisat full waveforms in U.S. coastal oceans in accordance with a deep-ocean reference waveform to remove land echoed signals before applying retrackers. All mentioned methods are satisfactory in significantly narrowing the differences between retracked SSHs and tide gauges or geoid models; however, the problem of waveforms whose leading edges are seriously affected by land remains unsolved. In addition to removing the part of nonocean-reflected waveforms, Halimi et al. (2013) have directly fitted Jason-2 simulated waveforms using the Brown model with symmetric and asymmetric Gaussian peak models to reduce the contamination of multi-peak signals reflected from land, and they concluded that mixed models perform better than the typical Brown model. The optimal retracker applied on radar waveforms varies according to the study area; therefore, the scheme to select a suitable retracker, which is an indispensable procedure, is by analyzing the shape of returned waveforms, and the optimal retracker varies according to the characteristics of the study areas (Lee et al., 2010; Kuo et al., 2012).

A number of studies have been carried out to improve the conduct of coastal altimetric measurements. SSHs derived from complex altimetric waveforms within $5 \mathrm{~km}$ from coasts remain an enormous challenge. Three ascending and two descending ground tracks of Envisat altimetry pass along coastal oceans in Taiwan (Figure 1). The land topography, ocean bathymetry, and ocean tides around Taiwan are highly diverse; thus, each ground track passes across a distinct land-sea transition area, which is favorable in analyzing coastal altimetric waveforms reflected from surfaces of various characterristics and retracked by different retrackers. In the present study, a waveform retracking system was developed to process Envisat waveforms echoed from coastal oceans around Taiwan to retrieve accurate SSHs. The main process is fitting Envisat subwaveforms containing leading and trailing edges to the Brown model with multiple Gaussian peak models. The Gaussian models represent the peaks in the waveforms reflected from non-ocean surfaces, while the parameters of the Brown model are used to locate the midpoint of the leading edge or determine the retracked gate. The waveforms not echoed by the ocean are then automatically removed. To evaluate the performance of the waveform retracking system and of different retrackers, retracked SSHs are compared with tide gauge records and geoid heights. Moreover, the relations among the accuracy of Envisat retracked SSHs, sea-land area environment, and ground track across the coastline from land to ocean and vice versa are discussed in detail.

Table 1. Information of the 10 Study Areas

\begin{tabular}{lllll}
\hline & Ocean tide & Bathymetry $^{*}$ & Land Topography & Ground track $^{* *}$ \\
\hline Kaohsiung Harbor & Low & Shallow & Jianan Plain: flat; sandbank offshore & L2O \\
Linshanbi Harbor & Middle & Shallow & Tatun volcanoes (10 km inshore): steep & L2O \\
Area A-1 & High & Shallow & Hsinchu Plain: flat; coastal wetland & L2O \\
Area A-2 & High & Shallow & Changhua Plain: flat & L2O \\
Area A-3 & Low & Shallow & Tableland: steep & L2O \\
Heping Harbor & Low & Deep & Central Mountain Range: steep & O2L \\
Waipu Harbor & High & Shallow & Holong River Alluvial Plain: flat & O2L \\
Area B-1 & Low & Shallow & Tatun volcanoes: rising slowly & O2L \\
Area B-2 & Low & Shallow & Central Mountain Range: steep & O2L \\
Area B-3 & Low & Deep & Coastal Range: steep & O2L \\
\hline
\end{tabular}

deep ocean $>200 \mathrm{~m}$; shallow ocean < $200 \mathrm{~m}$.

** O2L: ground tracks from ocean to land; L2O: ground tracks from land to ocean. 


\section{Study Area and Data}

Three ascending and two descending Envisat ground tracks pass across the coastlines of Taiwan in 10 land-sea transition areas where altimetry waveforms are processed using the retracking system in this study. Four of the study areas have nearby tide gauge stations, which are located at Linshanbi Harbor of New Taipei City, Waipu Harbor of Miaoli County, Kaohsiung Harbor of Kaohsiung City, and Heping Harbor of Hualien County. The actual locations of these harbors and the Envisat ground tracks are illustrated in Figure 1. The remaining six areas are classified according to the ground tracks approaching or receding from the land. Areas $\mathrm{A} 1$ to $\mathrm{A} 3$ and $\mathrm{B} 1$ to $\mathrm{B} 3$ represent the ground tracks moving from land to ocean and vice versa, respectively.

As shown in Table 1 and Figure 1, the land topography, ocean bathymetry, and ocean tide of these 10 areas are extremely diverse. Moreover, in 50\% of these areas, the Envisat ground tracks move toward the land, whereas the other $50 \%$ of the areas have ground tracks running reversely. The previously mentioned factors characterize the 10 different areas, making them suitable for the research purposes of this study, namely, evaluating the accuracy of retracked Envisat measurements and analyzing the relation between retracked data accuracy and either the surrounding environment of the study areas or the ground tracks from land/ocean to ocean/ land.

In this study, Envisat RA-2 data acquired from Level-2 Sensor Geophysical Data Record are used to retrieve coastal SSHs. These data contain $18 \mathrm{~Hz}$ 128-sample waveforms, corresponding to an along-track distance of $400 \mathrm{~m}$, with 35 -day repeat period from cycles 10 to 90 (from November 2002 to July 2010). The recommended corrections include standard instrument, media (ionosphere, and wet and dry troposphere corrections), and geophysical corrections (solid Earth tides, ocean tides, pole tide, orbit and inverted barometer). With the failure of the $\mathrm{S}$ band onboard dual-frequency Envisat altimeter in January 2008, the 2-h interval Global Ionospheric Maps broadcasted by NASA/JPL have been utilized to calculate ionosphere delay. The wet troposphere delay was derived from the operational numerical weather prediction model of the European Center for Medium-Range Weather Forecasts because of the degraded accuracy of the microwave radiometer in nearby coastal regions (Tseng et al., 2014). The ground tracks of Tracks $046,225,318,454$, and 497 in the oceanic vicinity of Taiwan, as shown in Figure 1, are used in this study.

When the ground tracks of Envisat altimetry gradually approach coastlines, reflected waveforms could be contaminated by land topography, shallow water, estuary, and wetlands, and then complications will be encountered. The footprints and waveforms of cycle 40 Envisat Track 318 near Waipu Harbor are demonstrated as an example in Figures 2 and 3. Waveforms 1 to 3 are typical Brown ocean ones (Brown, 1977) located approximately $10 \mathrm{~km}$ from the footprint 28 ; thus, $\mathrm{SSH}$ can be retrieved accurately by the default gate of 46 . From waveforms 4 to 16 , a single-peak subwaveform echoed from

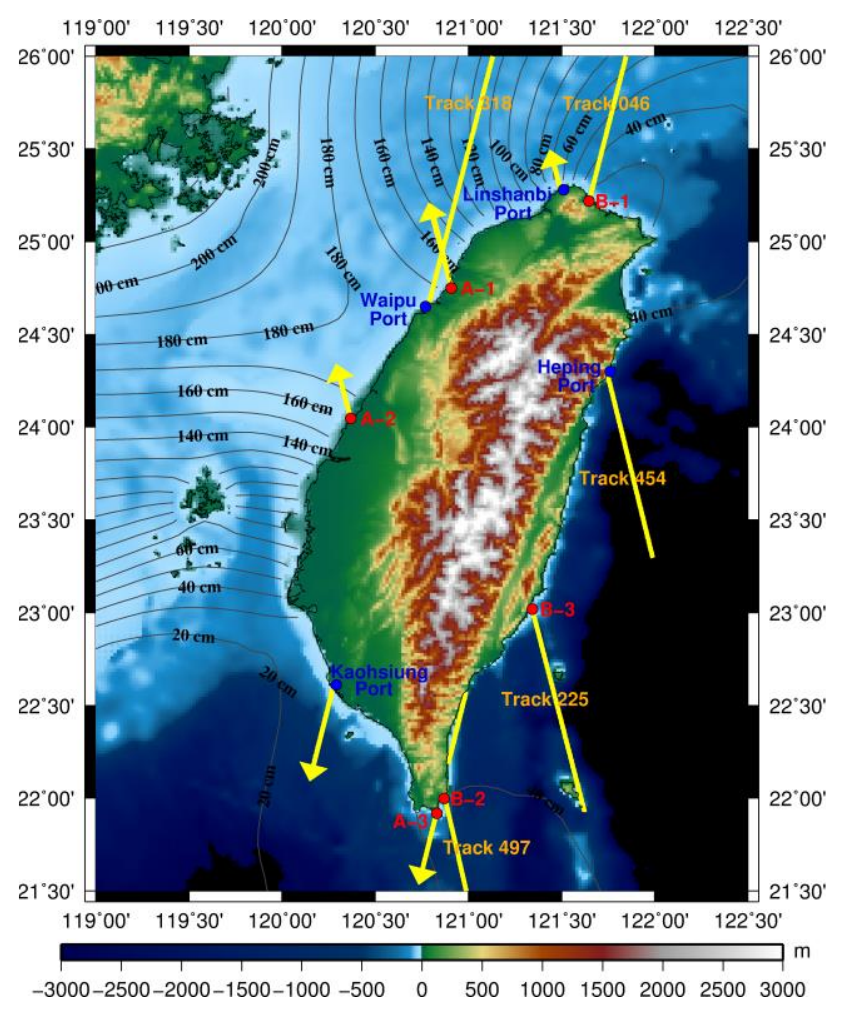

Figure 1. Illustration of the study areas. The amplitude of the M2 ocean tide from NAO.99jb (contour; Matsumoto et al., 2000) and the bathymetry around Taiwan from ETOPO1

(background color; Amante and Eakins, 2009). The Envisat ground tracks around Taiwan (yellow lines; the arrows represent ascending and descending tracks) and tide gauges used to assess retracked data (blue and red circles).

the land surface appears in the trailing edge and then moves gradually toward the leading edge. In waveforms 17 to 20, land-returned subwaveforms strongly contaminate the leading edges of full waveforms, causing difficulties in determining the true maximum amplitude of ocean waveforms. Some retrackers, such as offset center of gravity (Bamber, 1994) and threshold retrackers (Davis, 1997) that locate the midpoint of the leading edge based on the maximum amplitude, could possibly fail. Waveform 21 around $2.7 \mathrm{~km}$ from the footprint 28 is seriously hampered by land and contains multiple peaks, which no longer conforms to the Brown model. In addition, the leading edges of waveforms 24 to 27 further move backwards at the gates, causing the default gate to impossibly represent the midpoint of the leading edge to retrieve SSHs accurately, but ocean waveforms still obviously appear in full waveforms. After waveform 28, radar pulses are echoed from the flat land; thus, the reflected waveforms are nearly the same as land specular (quasi-specular) waveforms. Figure 3 illustrates an evolution of typical coastal waveforms. Coastal waveforms vary in different regions because of factors such as land topography, ocean bathymetry, coastal coral reef and wetland, and ocean tide. In addition, automatic gain control 


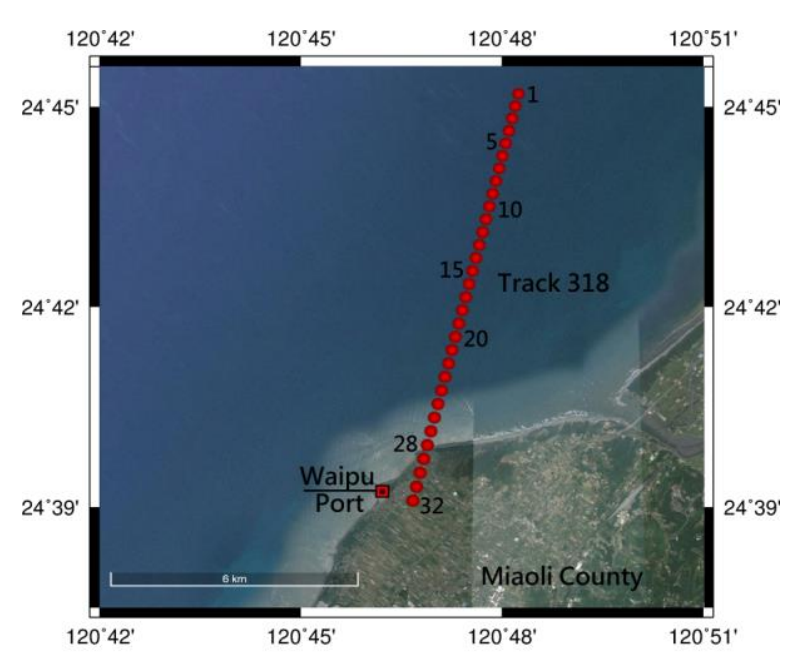

Figure 2. Coastal footprint of Envisat Track 318 (cycle40) around the Waipu Harbor (red square) of the Miaoli County (background map courtesy of Google Earth).

Table 2. Information of the Tide Gauge Stations Used in the Study

\begin{tabular}{lll}
\hline Station & Time interval & Provider \\
\hline Heping & $2007 / 07 \sim 2011 / 10$ & $\begin{array}{l}\text { He-Ping Industrial } \\
\text { Port Corporation }\end{array}$ \\
Waipu & $2003 / 07 \sim 2010 / 09$ & Central Weather Bureau \\
Kaohsiung & $2004 / 03 \sim 2012 / 12$ & Ministry of the Interior \\
Linshanbi & $2003 / 11 \sim 2012 / 12$ & Central Weather Bureau \\
\hline
\end{tabular}

(AGC) processes differ when satellite moves through coastlines from ocean to land and vice versa; thus, waveforms evolve differently and are totally irreversible (Chang et al., 2006). Because of the lag effect of AGC and different or mixed characteristics of the reflected surfaces in the coastal regions, the ordinate units are not consistent throughout all the subfigures in Figure 3.

The accuracy of coastal retracked SSHs was evaluated using 6-min averaged tide gauge records and a geoid model. To compare with retracked SSHs, identical corrections were applied to the tide gauge records, which were detided by the harmonic tidal analysis method (Franco, 1988). The detailed information of the tide gauge stations is listed in Table 2. Geoid heights are derived from Earth Gravitational Model 2008 (EGM-2008) that is provided by the National Geospatial-Intelligence Agency. EGM2008 refers to the ellipsoid of WGS84 with spherical harmonic coefficients completed to degree 2190 and order 2159, which correspond to the spatial resolution of $9.3 \mathrm{~km} \times 9.3 \mathrm{~km}$ in the equator (Pavlis et al., 2012).

\section{Methodology}

Satellite altimetry is a developed technology in oceanography to synoptically map global ocean surfaces. The basic concept of observation is straightforward. The range measurement $R$ from the satellite to the ocean surface is calculated using the round-trip travel time $(t)$ of a transmitted electromagnetic radar pulse between the radar altimeter and the instantaneous sea surface. The equation can be expressed as:

$R=c t / 2$

where $c$ is the speed of light in vacuum.

SSHs relative to a specified reference ellipsoid, are written as follows (Kuo, 2006):

$h_{s s h}=H-\left(R+\sum_{i} h_{i}\right)$

where $H$ is the orbital height from the satellite to a specified reference ellipsoid and $h_{i}$ are all the recommended corrections.

In practice, $t$ is determined by the default gate that is to locate the midpoint of the leading edge in altimetric waveform, which is actually a time series of the received power distributions of the reflected pulses. An example is default gate 46 of the 128 sample waveforms for Envisat. However, reflected waveforms become more complex in the coastal regions as a result of land contamination; thus, the midpoint of the leading edge deviated from the default gate and the waveform retracking technique should be applied to improve the retrieved accurate SSHs. The retracked range correction $\Delta R$ corrected to $R$ can be expressed as:

$\Delta R=\left(G_{\text {retracked }}-G_{\text {default }}\right) \times c \tau / 2$

where $G_{\text {retracked }}$ is the retracked gate, $G_{\text {default }}$ is the default tracking gate of the ocean waveform, and $\tau=3.125$ nanoseconds.

To address land contamination in the waveforms echoed from the study areas, a comprehensive retracking system that includes a novel retracker and an automatic mechanism to remove non-ocean waveforms was developed in this study. The procedure of the waveform retracking system is described in detail as follows (Figure 4):

(a) Extraction of altimetric subwaveforms: To avoid the pre-leading edge jumps in the waveforms that could degrade the accuracy of the retracked SSHs (Figure 5), approximate leading edge was initially determined for the extraction of subwaveforms that contained the leading and trailing edges. The leading edge is characterized by the power difference of two gates with a specific interval that is relatively large, and the maximum difference could be regarded as the approximate leading edge. We calculate the power differences according to Equation (4) (black solid curve in Figure 5) and found the maximum difference that will locate $K$ (black dashed line in Figure 5). The equation to compute the power difference can be expressed as:

$D P(k)=P(k+3)-P(k-3)$ 

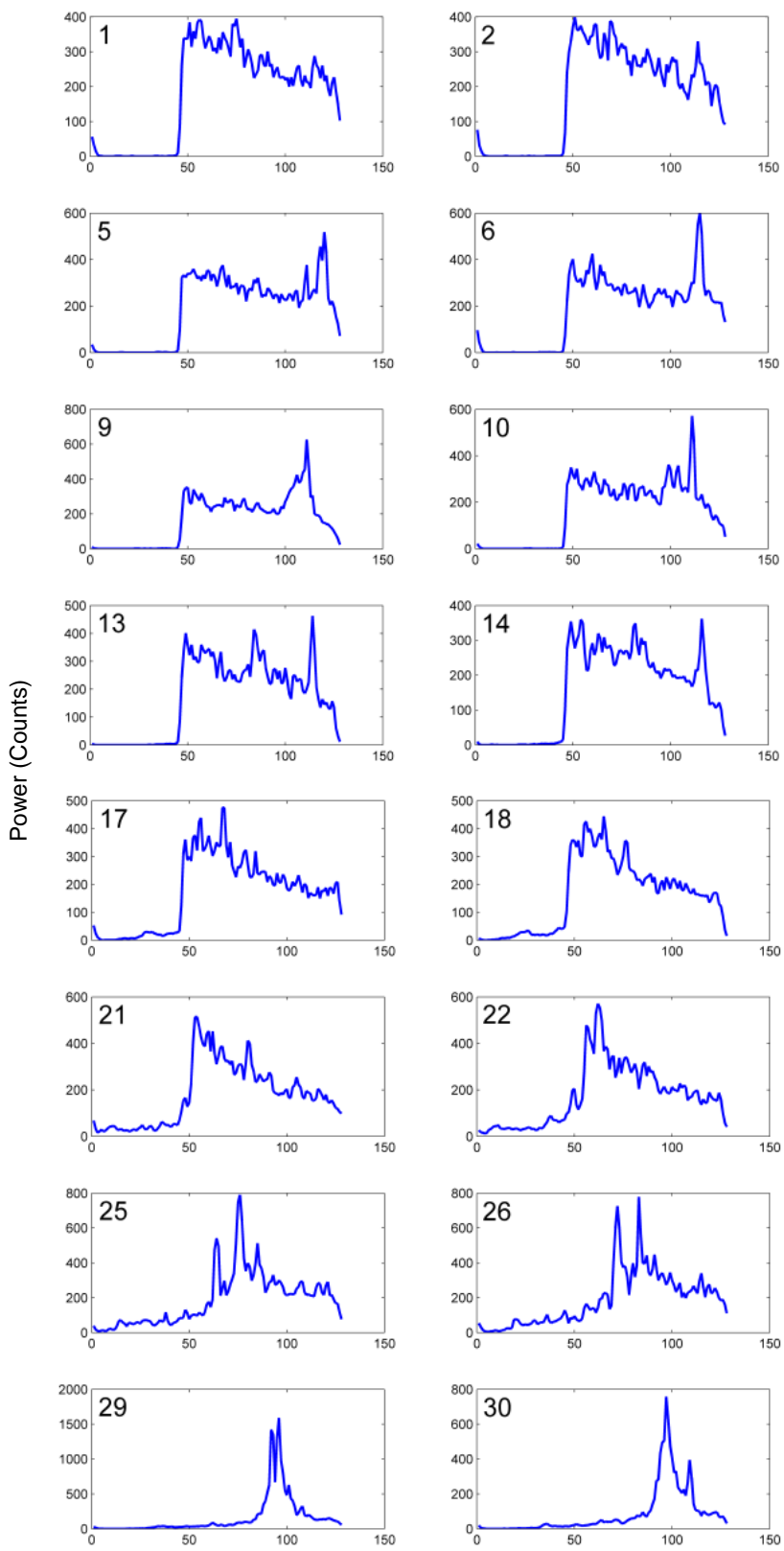
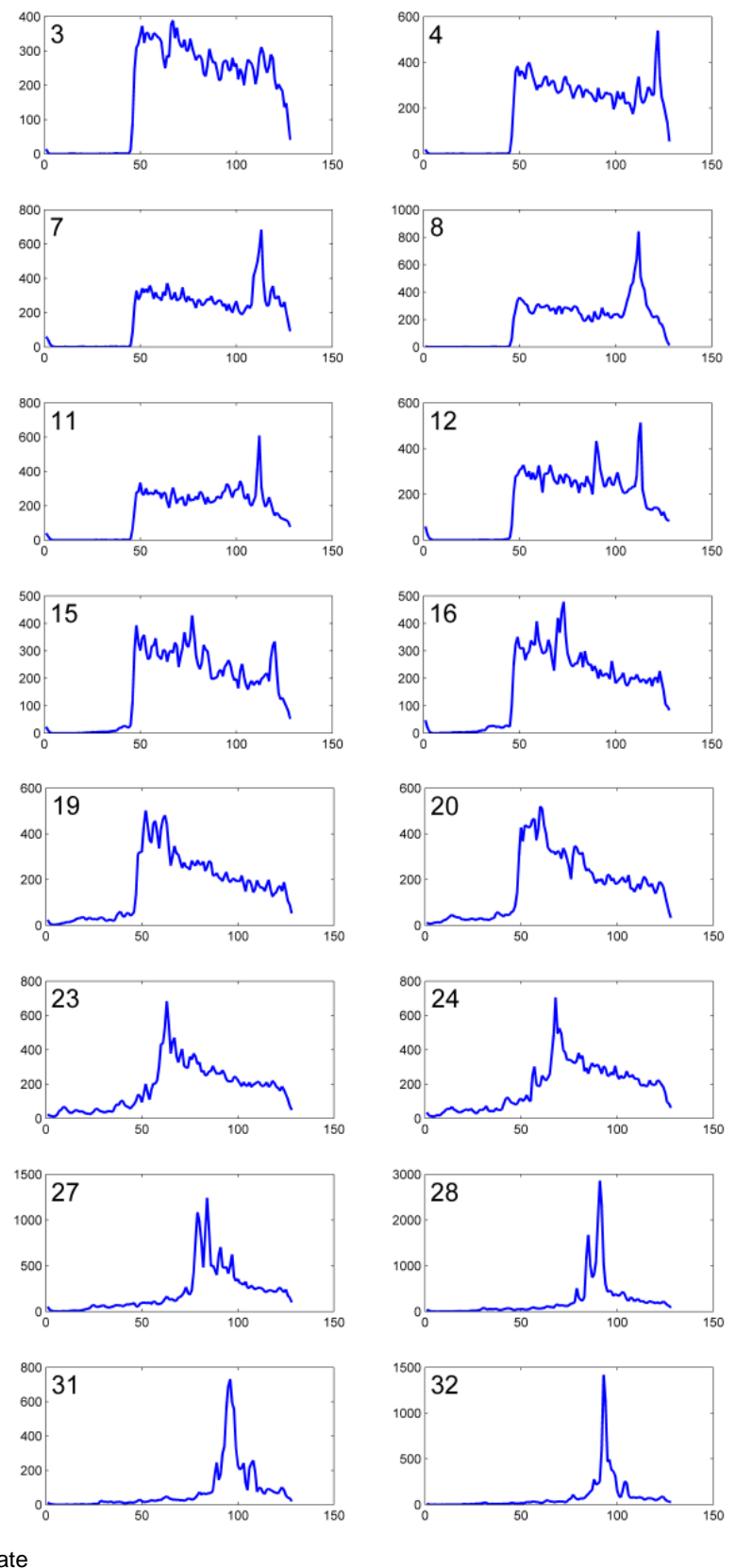

Figure 3. Coastal waveforms of Envisat Track 318 (cycle 40) near Waipu Harbor of Miaoli County. The waveform index corresponds with the location index in Figure 2.

where $P(k+3)$ and $P(k-3)$ are the powers of the returned waveforms at gates $k+3$ and $k-3$, respectively.

Afterwards, gates $(K-10)$ to 128 in the full waveform were selected as subwaveforms for the succeeding waveform retracking process. Before calculating $D P(k)$, altimetric waveforms were smoothened using a moving average filter with a window size of 5 gates to reduce noises or high-frequency signals. Applying the filter to the reflected waveforms could help to determine the maximum of power differences easily and correctly.

(b) Calculation of the number of peaks and their location gates: The simplification of the Brown model can be expressed as (Halimi et al., 2013):

$P_{B}(k)=\frac{A_{B}}{2}\left[1+\operatorname{erf}\left(\frac{k-m-\alpha \sigma_{c}^{2}}{\sqrt{2} \sigma_{c}}+1\right)\right] e^{-\alpha\left(k-m-\frac{\alpha \sigma_{c}^{2}}{2}\right)}+N_{t}$ 


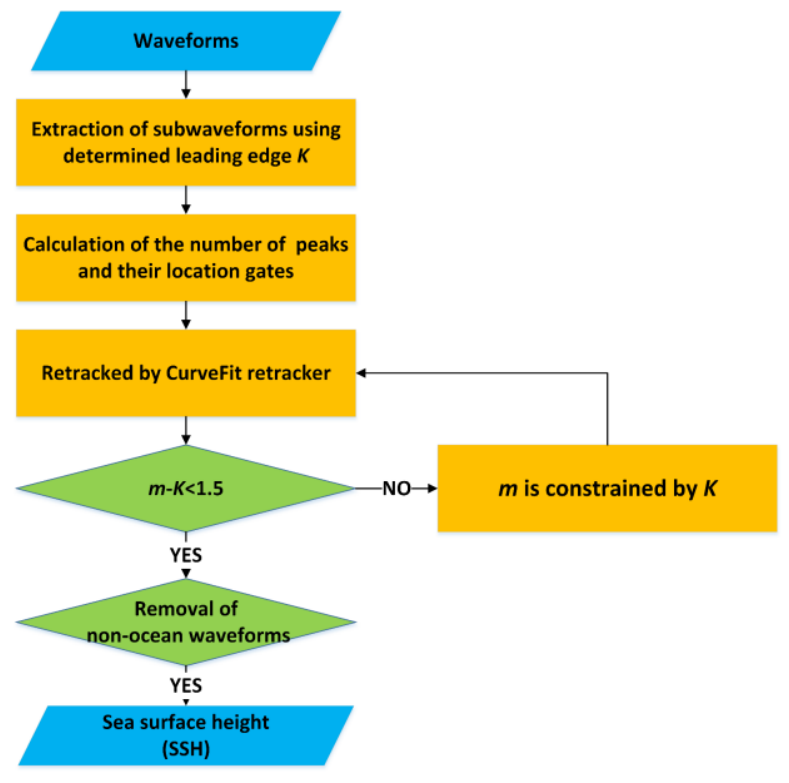

Figure 4. Flowchart of the waveform retracking system developed in this study.

where $P_{B}(k)$ is the received waveform at the $k^{\text {th }}$ gate, $A_{B}$ is the amplitude, erf is the Gaussian error function, $m$ is the midpoint gate of the leading edge, $\alpha$ is an exponential decay parameter in the trailing edge, $\sigma_{c}$ is the slope of the leading edge controlled by significant wave height, and $N_{t}$ is thermal noise.

The Gaussian model can be written as (Goshtasby and O'Neill, 1994):

$$
P_{G}(k)=A_{G} e^{-(k-p)^{2} / 2 \beta^{2}}
$$

where $P_{G}(k)$ is the received waveform at the $k^{\text {th }}$ gate, $A_{G}$ is the amplitude of the peak, $p$ is the gate of the peak, and $\beta$ is related to the peak width.

Table 3. Statistics of the Brown Model Parameters from Waveforms of Envisat Track 454 approximately $50 \mathrm{~km}$ Offshore

\begin{tabular}{lllll}
\hline & $\mathrm{A}_{\mathrm{B}}$ & $\mathrm{m}$ & $\alpha$ & $\sigma_{\mathrm{c}}$ \\
\hline Mean & 414.9 & 47.12 & 0.012 & 1.00 \\
STD & 19.3 & 0.13 & 0.001 & 0.19 \\
\hline
\end{tabular}

To create a fitting model that combined the Brown model with multiple Gaussian peak models, the amount of land waveforms (peaks) and the locations of these waveforms were determined first. These waveforms were detected using a local maximum with a criterion that the power difference between the ocean reference waveform and the actual coastal waveform is larger than the threshold value of 50. Therefore, power differrences those were lower than 50 were considered as

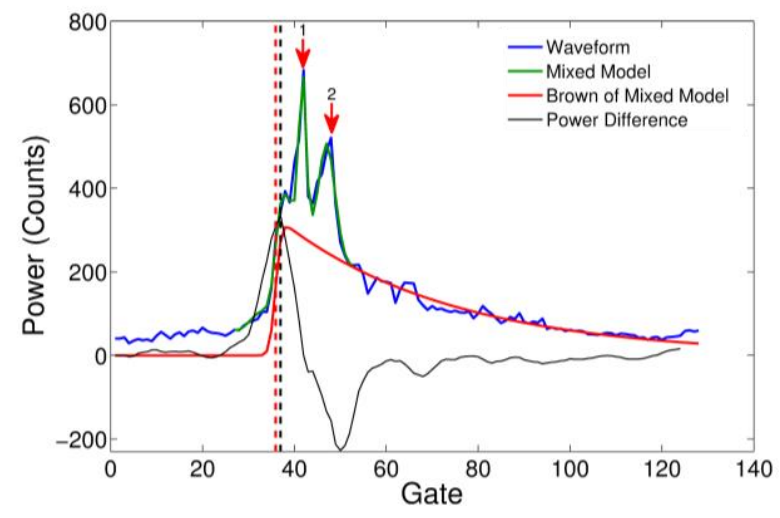

Figure 5. Illustration of Envisat coastal altimetric waveform (blue curve), power differences (black solid curve), approximate leading edge, number and locations of land waveform peaks, midpoint $\mathrm{m}$ (red dashed line), and approximate midpoint $\mathrm{K}$ (black dashed line) of the leading edge. The green and red curves are reconstructed waveforms from all the estimated parameters and the estimated Brown parameters of the mixed model, respectively.

noises rather than peaks. The adopted threshold value of 50, which was regarded as the maximum random noise, was calculated by averaging the power deviations of each deepocean waveform from the mean of each waveform. As shown in Figure 5, two peaks were found in this complex returned waveform.

(c) Fitting subwaveforms to the Brown ocean plus Gaussian models: The combined model can be expressed as:

$$
\begin{aligned}
P_{T}(k)= & P_{B}(k)+P_{G, i}(k) \\
= & \frac{A_{B}}{2}\left[1+\operatorname{erf}\left(\frac{k-m-\alpha \sigma_{c}^{2}}{\sqrt{2} \sigma_{c}}+1\right)\right] e^{-\alpha\left(k-m-\frac{\alpha \sigma_{c}^{2}}{2}\right)} \\
& +N_{t}+A_{G, i} e^{-\left(k-p_{i}\right)^{2} / 2 \beta^{2}}
\end{aligned}
$$

where $i$ is the number of peaks detected in the previous step.

Altimetric waveforms were used as observations $P_{G}(k)$, and the unknown parameters $A_{B}, m, \alpha, \sigma_{c}, N_{t}, A_{G}, p$, and $\beta$ were estimated by the least squares method. The estimated $m$ (red dashed line in Figure 5) was assumed to be close to $K$ (black dashed line in Figure 5) during the calculation in step (a); thus, the gate difference of $m$ and $K$ was evaluated using the threshold of 1.5 gates, which was empirically calculated using Heping tide gauge records and retracked altimetry data. If the gate difference was larger than 1.5 gates, which mostly occurred when the leading edge of the waveform was severely contaminated by land, nonlinear fitting was performed again by constraining the unknown parameter $m$ using $K$ with a variation of \pm 0.1 gates. The retracker is hereafter called in this study as CurveFit retracker. Finally, the estimated gate $m$ was substituted into Equation (3) as $G_{\text {retracked }}$ to calculate the range correction. 
Table 4. STDs of Differences between EGM2008 Geoid Heights and Retracked Altimetric SSHs before or after Removing Non-ocean Reflected Waveforms in All Study Areas

\begin{tabular}{lllllll}
\hline Method & Distance $(\mathrm{km})$ & OT $(\mathrm{m})$ & 50TR $(\mathrm{m})$ & 50MTR $(\mathrm{m})$ & Non-retracked $(\mathrm{m})$ & Number of data \\
\hline Before removing & 0 to 5 & 1.109 & 1.189 & 1.180 & 3.825 & 10,707 \\
& 5 to 10 & 0.282 & 0.434 & 0.423 & 1.601 & 10,953 \\
After removing & 0 to 5 & 0.636 & 0.771 & 0.737 & 2.184 & 6,843 \\
& 5 to 10 & 0.244 & 0.337 & 0.312 & 1.025 & 10,619 \\
\hline
\end{tabular}

(d) Removal of non-ocean reflected waveforms: Four parameters of the Brown model, namely, $A_{B}, m, \alpha$, and $\sigma_{c}$, which were estimated in the previous step, were used to distinguish ocean waveforms from non-ocean waveforms. First, the selection criteria of the four parameters were established. In the present study, the statistics of the Brown model parameters were calculated using the deep-ocean waveforms of Envisat Track 454 approximately $50 \mathrm{~km}$ off the eastern Taiwan coast (as shown in Table 3). The statistics were further verified using waveforms in other regions, and the statistical results yielded similar statistical values. Based on the statistics of the four parameters, the ocean waveform should fulfill the following criteria assumed in this study: $A_{B}>200,22<m<66, \alpha<0.03$, and $\sigma_{c}<3$.

(e) Validation of retracked SSHs: In addition to the retracker developed in this study, three commonly used retrackers were adopted to retrieve altimetric SSHs: ocean retracker (OR) (CLS, 1997), 50\% threshold retracker (50TR) (Davis, 1997), and 50\% modified threshold retracker (50MTR) (Lee et al., 2008). Altimetric SSHs retracked by other retrackers, which are not mentioned in this paper, have less valid measurements after excluding the outliers defined as the difference between retracked SSH and EGM2008 larger than $5 \mathrm{~m}$. Retracked altimetric SSHs are finally compared with tide gauge records and geoid heights derived from EGM2008 to evaluate the performance of the self-developed retracking system and retrackers.

\section{Results and Discussions}

The newly developed retracking system in this study has the ability to remove non-ocean reflected waveforms. The accuracy of the retracked altimetry SSHs in the 10 study areas is first examined by comparing with EGM2008 geoid heights. As shown in Table 4, the accuracy significantly improved within $0 \mathrm{~km}$ to $5 \mathrm{~km}$ of the ocean from the coasts, with STDs reduced by 35 to $43 \%$. For example, the STD of differences between retracked SSHs by OR and EGM2008 is reduced from 1.109 to $0.636 \mathrm{~m}$ (43\% reduction) after non-ocean waveforms are removed. This finding proves that the retracking system can effectively discard waveforms that do not belong to a typical ocean model. Waveforms within 0 to $5 \mathrm{~km}$ offshore are contaminated by land topography and the lag effect of AGC. The amplitude of ocean-reflected waveforms is therefore relatively small compared with that of land waveforms, and the number of valid measurements apparently decreases with the exclusion of $34 \%$ data. AGC loop maintains the digitized receiver output at a nearly constant level regardless of variations in the backscatter (Smith and Scharroo, 2015). Given the coastal land topography, the powers of the echoed waveforms fluctuate continuously. Therefore, AGC has to adjust successively according to the power of the preceding echoed waveforms (Remy et al., 1990; Chang et al., 2006). Consequently, SSHs derived from contaminated altimetric waveforms are relatively low in accuracy within 0 to 5 $\mathrm{km}$ from coasts.

As shown in the last column of Table 6, the reflected waveforms from the coasts are mostly effective and contain notable ocean signals in the case of Envisat ground tracks from ocean to land. For example, $91 \%$ of the observations within 0 to $5 \mathrm{~km}$ offshore of the Heping Harbor are valid. By contrast, as the ground track passes the coastline from land to ocean, the amount of effective waveforms substantially decrease, especially in areas with coastal wetlands or sandbanks, such as in Kaohsiung Harbor and in the A-1 areas where $65 \%$ and $62 \%$ of measurements were removed, respecttively. Before entering the ocean surrounding the Linshanbi Harbor, the
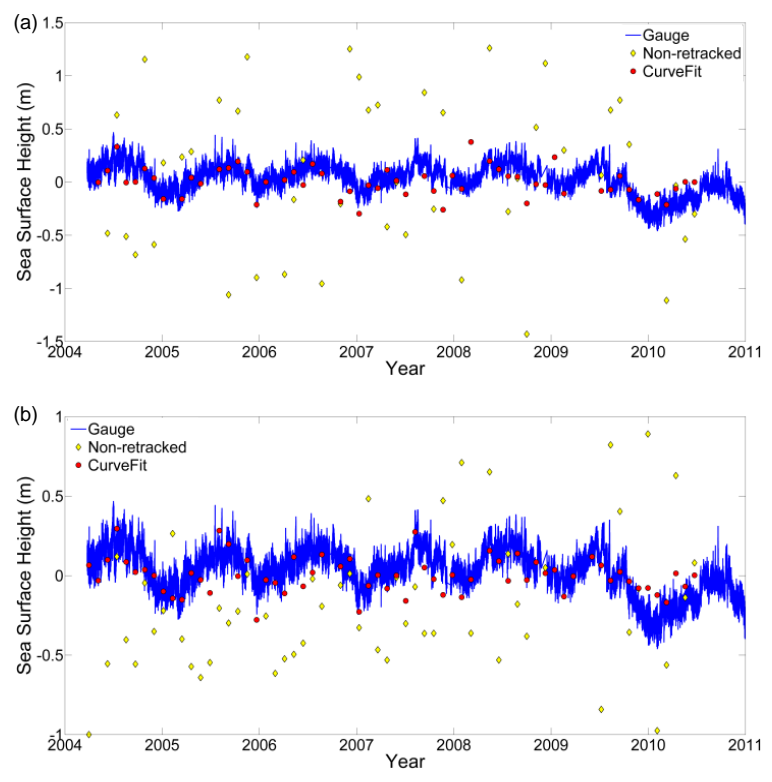

Figure 6. SSH time series in Kaohsiung Harbor derived from altimetry and tide gauge records (The mean of SSHs was removed: left: 0 to $5 \mathrm{~km}$ zone; right: 5 to $10 \mathrm{~km}$ zone). The blue curve shows the Kaohsiung tide gauge records.

The yellow diamonds and red circles are non-retracked and retracked SSHs, respectively, by the CurveFit retracker (non-retracked SSHs beyond the Y-axis range are not presented). 
ground track initially passes through the Tatun volcanoes where topography changes dramatically, causing a trackingloop response problem (Remy et al., 1990; Smith and Scharoo, 2015). Consequently, no valid waveform is available within 0 to $5 \mathrm{~km}$ from the coast.

Within 5 to $10 \mathrm{~km}$ from the coasts, the effects of land topography and AGC response on altimetric waveforms are mitigated. Thus, the waveforms correspond to the typical Brown model, and the number of valid data is almost consistent after eliminating non-ocean waveforms, where only $1 \%$ of the measurements are removed. The STDs of differences between retracked SSHs and EGM2008 geoid heights are slightly reduced by $15 \%$ at most.

In this study, Envisat retracked SSHs are first evaluated using the improvement percentages (IMPs) derived from the STDs of differences between tide gauge records and retracked or non-retracked heights in the four study areas (Hwang et al., 2006). To be noticed, only when the SSHs retracked by five retrackers were all valid can they be used for the comparison. As shown in Table 5, the accuracy of retracked SSHs significantly improved compared with that of non-retracked SSHs. After waveform retracking techniques are applied, the STDs of differrences in both $0-5 \mathrm{~km}$ and $5-10 \mathrm{~km}$ zones from the coasts are lowered from $0.728-1.196 \mathrm{~m}$ to $0.111-0.420 \mathrm{~m}$ and from $0.249-2.145 \mathrm{~m}$ to $0.107-0.225 \mathrm{~m}$, respecttively, with a maximum IMP reaching $93 \%$.

The CurveFit retracker developed in this study exhibited outstanding performance except in the 5 to $10 \mathrm{~km}$ zone from the coast surrounding Heping Harbor. In the 0 to $5 \mathrm{~km}$ zone, the CurveFit retracker also obtained satisfactory IMPs of 57 to $89 \%$ and showed a large improvement at the Kaohsiung Harbor, with reduced STD of differences from 1.196 to $0.133 \mathrm{~m}$ and $89 \%$ IMP. Figure 6 illustrates that non-retracked SSHs reflected a large deviation from Kaohsiung tide gauge records and retracked SSHs by the CurveFit retracker in the 0 to $5 \mathrm{~km}$ and 5 to $10 \mathrm{~km}$ zones. The results well agree with the gauge data and can represent annual coastal sea level variations. The main reason for the better performance of the CurveFit retracker is fitting altimetric subwaveforms to the Brown model with Gaussian models. Therefore, the determined midpoint of the leading edge is not degraded by contaminated land signals. Compared with other retrackers, the CurveFit retracker is a better algorithm performed in an area where land topography and AGC response have significant effects.

Table 5. STDs of Differences between Coastal Altimetric SSHs and Tide Gauge Records

\begin{tabular}{lllllllll}
\hline & Study area & $\begin{array}{l}\text { Distance from } \\
\text { coasts }(\mathrm{km})\end{array}$ & $\begin{array}{l}\text { CurveFit } \\
(\mathrm{m})\end{array}$ & $\begin{array}{l}\text { Ocean } \\
(\mathrm{m})\end{array}$ & $\begin{array}{l}\text { 50TR } \\
(\mathrm{m})\end{array}$ & $\begin{array}{l}\text { 50MTR } \\
(\mathrm{m})\end{array}$ & $\begin{array}{l}\text { Non-retracked } \\
(\mathrm{m})\end{array}$ & $\begin{array}{l}\text { IMP of CurveFit } \\
(\%)\end{array}$ \\
\hline L2O $^{*}$ & Linshanbi & 0 to 5 & & & \multicolumn{5}{c}{ No Data } \\
& Harbor & 5 to 10 & $\mathbf{0 . 1 4 9}$ & 0.637 & 0.472 & 0.295 & 2.145 & 93 \\
& Kaohsiung & 0 to 5 & $\mathbf{0 . 1 3 3}$ & 0.706 & 0.843 & 0.818 & 1.196 & 89 \\
& Harbor & 5 to 10 & $\mathbf{0 . 1 0 7}$ & 0.114 & 0.174 & 0.133 & 0.679 & 84 \\
O2L $^{* *}$ & Heping Harbor & 0 to 5 & $\mathbf{0 . 1 1 1}$ & 0.157 & 0.216 & 0.146 & 0.728 & 85 \\
& & 5 to10 & 0.117 & 0.160 & 0.132 & $\mathbf{0 . 1 1 4}$ & 0.311 & 62 \\
& Waipu Harbor & 0 to 5 & $\mathbf{0 . 4 2 0}$ & 0.450 & 0.822 & 0.760 & 0.972 & 57 \\
\hline
\end{tabular}

* L2O: ground track from ocean to land.

${ }^{* *} \mathrm{O} 2 \mathrm{~L}$ : ground track from land to ocean.

${ }^{* * * *}$ The bold represent the smallest STD in each area.
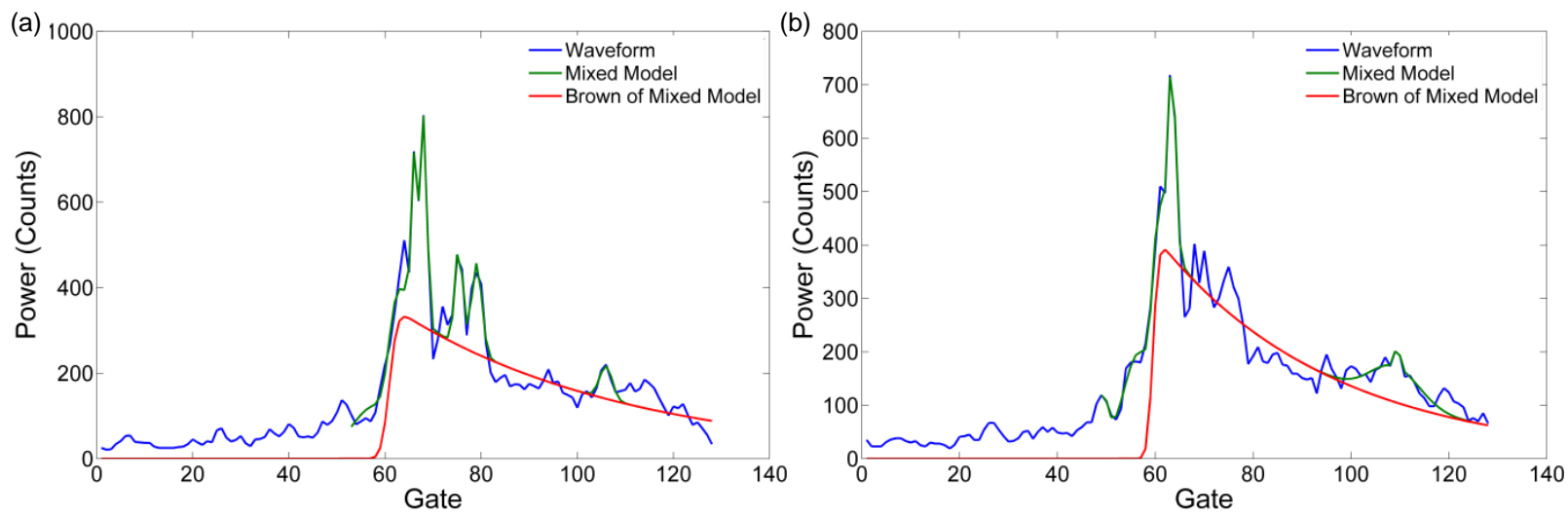

Figure 7. Complex reflected waveforms of Envisat Track 318 (cycle 30) in the 0 to $5 \mathrm{~km}$ zone near Waipu Harbor (blue curve). The green and red curves are reconstructed waveforms from all the estimated parameters and the estimated

Brown parameters of the mixed model, respectively. 
The STD of differences between retracked altimetry and tide gauge data in the 0 to $5 \mathrm{~km}$ zone around Waipu Harbor is larger than those in the other three areas. The underlying cause is that coastal land topography is an alluvial plain of downstream Holong River. With the heavy land topography contamination of the leading edges of echoed waveforms, bias is encountered in the retracked midpoints obtained by the CurveFit retracker, resulting in $m$-level error in the altimetric range (Figure 7). Within 5 to $10 \mathrm{~km}$ off the coast, the CurveFit retracker only has $10 \%$ IMP and the STD is $0.225 \mathrm{~m}$, which is slightly larger than those in the other three areas. Larger STDs may emerge from the complex and higher ocean tides of up to 1 to $2 \mathrm{~m}$ (Figure 1 ).

Within $5 \mathrm{~km}$ to $10 \mathrm{~km}$ off the coast, especially around the Heping Harbor, altimetric waveforms in deep oceans less affected by land topography and AGC response conform to the traditionnal ocean model. Therefore, all retrackers perform equally and lower STDs from more than $30 \mathrm{~cm}$ to less than 20 $\mathrm{cm}$.

To evaluate the reliability of retracked SSHs in all 10 study areas, geoid heights derived from EGM2008 instead of tide gauges are employed to compute STDs of differences and IMPs. As shown in Table 6, the CurveFit retracker is the best performing retracker in all the test areas within 0 to $5 \mathrm{~km}$ offshore, with IMPs exceeding 70\%, except in the A-1 area where the coastal region is wetland. In the ocean within $5 \mathrm{~km}$ to $10 \mathrm{~km}$ offshore, the STDs of differences between retracked SSHs and EGM2008 geoid heights are all smaller than $0.3 \mathrm{~m}$ and most of STDs are below $0.2 \mathrm{~m}$. Except in the study area near Waipu Harbor, the figures obtained by the CurveFit retracker showed excellent improvement, with IMPs ranging from 12 to $92 \%$.

As Envisat ground track moves from land to the ocean, the accuracy of the non-retracked altimetric SSHs becomes extremely low and the number of SSHs considerably decreases in response to land topography and AGC low response. In this study, after applying waveform retracking, the accuracy of retracked SSHs significantly improved. By contrast, as the ground track passed through the coastline from ocean to land, the accuracy of non-retracked SSHs increased, especially in the 5 to $10 \mathrm{~km}$ zone where waveforms were more similar to the Brown model. Thus, equal performance was shown by all retrackers. In addition, the CurveFit retracker developed in our study can effectively reduce land contamination in reflected waveforms. The accuracy of the retracked SSHs along the ground track from land to ocean exhibited a more significant improvement than that from ocean to land.

Coastal terrain gradient is also a principal factor affecting altimetric accuracy. If the ground track passes through undulating land before approaching the ocean, not only land topography and AGC response significantly decrease the accuracy of SSHs, but also the slow response of tracking loop. In the Linshanbi Harbor and A-3 study areas, for example, the STDs of differences derived from non-retracked SSHs were at the meter level, and the measurements within 0 to $5 \mathrm{~km}$ from the coast around Linshanbi Harbor were entirely unusable. After the CurveFit retracker was applied to process the waveforms, the STDs of differences in these two areas were reduced from

Table 6. STDs of Differences between Coastal Altimetric SSHs and EGM2008 Geoid Heights

\begin{tabular}{|c|c|c|c|c|c|c|c|c|c|}
\hline $\begin{array}{l}\text { Fly } \\
\text { direction }\end{array}$ & $\begin{array}{l}\text { Study } \\
\text { areas }\end{array}$ & $\begin{array}{l}\text { Distance from } \\
\text { coasts }(\mathrm{km})\end{array}$ & $\begin{array}{l}\text { CurveFit } \\
\text { (m) }\end{array}$ & $\begin{array}{l}\text { Ocean } \\
(\mathrm{m})\end{array}$ & $\begin{array}{l}\text { Th } 50 \\
\text { (m) }\end{array}$ & $\begin{array}{l}\text { Lee } 50 \\
(\mathrm{~m})\end{array}$ & $\begin{array}{l}\text { UnRet } \\
(\mathrm{m})\end{array}$ & $\begin{array}{l}\text { IMP of } \\
\text { CurveFit (\%) }\end{array}$ & $\begin{array}{l}\text { Number of data } \\
\text { (removed/raw) }\end{array}$ \\
\hline \multirow[t]{10}{*}{$\mathrm{L} 2 \mathrm{O}^{*}$} & Linshanbi & 0 to 5 & \multicolumn{7}{|c|}{ No Data } \\
\hline & Harbor & 5 to 10 & 0.295 & 0.460 & 0.377 & 0.373 & 3.504 & 92 & $286 / 411$ \\
\hline & Kaohsiung & 0 to 5 & 0.257 & 1.213 & 1.180 & 1.148 & 3.258 & 92 & $367 / 1035$ \\
\hline & Harbor & 5 to 10 & 0.182 & 0.186 & 0.340 & 0.268 & 1.059 & 83 & $1133 / 1137$ \\
\hline & A-1 & 0 to 5 & 0.968 & 1.209 & 1.729 & 1.723 & 1.623 & 40 & $433 / 1131$ \\
\hline & & 5 to 10 & 0.247 & 0.363 & 0.474 & 0.348 & 0.898 & 72 & $1280 / 1307$ \\
\hline & A-2 & 0 to 5 & 0.390 & 0.682 & 0.948 & 0.888 & 1.354 & 71 & $869 / 1910$ \\
\hline & & 5 to 10 & 0.225 & 0.209 & 0.285 & 0.438 & 0.315 & 28 & $1253 / 1266$ \\
\hline & A-3 & 0 to 5 & 0.348 & 0.391 & 0.393 & 0.409 & 4.517 & 92 & $652 / 786$ \\
\hline & & 5 to 10 & 0.187 & 0.241 & 0.168 & 0.196 & 2.289 & 92 & $924 / 949$ \\
\hline \multirow[t]{10}{*}{$\mathrm{O} 2 \mathrm{~L}^{*}$} & Heping & 0 to 5 & 0.239 & 0.381 & 0.326 & 0.292 & 1.445 & 83 & $1066 / 1170$ \\
\hline & Harbor & 5 to 10 & 0.163 & 0.191 & 0.144 & 0.162 & 0.255 & 36 & $1149 / 1170$ \\
\hline & Waipu & 0 to 5 & 0.444 & 0.937 & 1.194 & 1.056 & 2.287 & 81 & $541 / 766$ \\
\hline & Harbor & 5 to 10 & 0.229 & 0.219 & 0.645 & 0.539 & 0.200 & -15 & $1063 / 1064$ \\
\hline & B-1 & 0 to 5 & 0.283 & 0.481 & 0.449 & 0.465 & 1.815 & 84 & $1011 / 1466$ \\
\hline & & 5 to 10 & 0.215 & 0.215 & 0.206 & 0.202 & 0.245 & 12 & $1226 / 1288$ \\
\hline & B-2 & 0 to 5 & 0.245 & 0.308 & 0.421 & 0.437 & 1.004 & 76 & $774 / 1124$ \\
\hline & & 5 to 10 & 0.186 & 0.210 & 0.210 & 0.165 & 0.279 & 33 & $1026 / 1040$ \\
\hline & B-3 & 0 to 5 & 0.231 & 0.379 & 0.379 & 0.302 & 1.782 & 87 & $1130 / 1319$ \\
\hline & & 5 to 10 & 0.182 & 0.215 & 0.207 & 0.229 & 0.301 & 40 & $1279 / 1321$ \\
\hline
\end{tabular}

* O2L: ground track from ocean to land; L2O: ground track from land to ocean.

${ }^{* *}$ The bold figures represent the smallest STD in each area. 
the meter level to the decimeter level, proving that the retracking system in this study can promote altimetric accuracy by detecting and removing the previously mentioned contaminations. The coastal land topography of Kaohsiung Harbor, A-1, and A-2 areas is simply plain. Moreover, because of the sandbank and wetland off Kaohsiung Harbor and the A-1 areas, respectively, the accuracy is lower than that in the A-2 area. In the A-1 area, the leading edge and the first gates of the trailing edge are heavily contaminated by Siangshan wetland. Hence, the midpoint of the leading edge cannot be accurately determined. Although the waveforms were processed beforehand by retrackers, the STD remains as high as approximately $1 \mathrm{~m}$.

While the ground track runs from ocean to land, waveforms are susceptible to land topography contamination, particularly flat plain. As shown in Table 6 , the result in the 0 to 5 $\mathrm{km}$ zone around Waipu Harbor indicates that non-retracked SSHs have a relatively low accuracy with an STD of $2.287 \mathrm{~m}$. Although the waveforms were already retracked, the STD remained high at $44 \mathrm{~cm}$. In the other four study areas, the STDs were less than $30 \mathrm{~cm}$, and most observations were valid. In addition to complex and large ocean tides, another possible reason is that the radar pulse reflected from the steep terrain cannot be received by the altimeter because of the direction of echoed radar signals or the elevation difference between the land and the ocean is too large for land waveforms to appear in the range window spanned by the waveform sample sequence.

\section{Conclusions}

A waveform retracking system that can retrack Envisat waveforms in the ocean within 0 to $10 \mathrm{~km}$ from the coast surrounding Taiwan has been successfully developed in this study to improve the accuracy of SSHs. This developed system includes a novel waveform retracker called CurveFit retracker and a mechanism for removing non-ocean returned waveforms. The mechanism can effectively remove non-ocean reflected waveforms within 0 to $5 \mathrm{~km}$ offshore. However, because most waveforms conform to the Brown ocean model within 5 to $10 \mathrm{~km}$ from the coast, the number and accuracy of valid measurements achieve the same level after the mechanism of removing non-ocean waveforms is applied.

The CurveFit retracker is evaluated as the most outstanding of all retrackers used in most study areas. In general, the IMP is higher within 0 to $5 \mathrm{~km}$ ocean from the coasts than that within 5 to $10 \mathrm{~km}$ ocean, which means the CurveFit retracker works excellently in the 0 to $5 \mathrm{~km}$ zone by solving the land contamination problem. Benefitting from coastal accurate SSHs, particularly in the 0 to $5 \mathrm{~km}$ zone from the coasts, more coastal ocean phenomena, such as coastal sea level and currents, can be unequivocally understood. This study also reveals that a number of participating factors could possibly affect the shape of returned waveforms and the accuracy of altimetry measurements. The dominant factors are coastal land topography and ground tracks approaching or leaving land. In addition, the effect of coastal land topography on reflected waveforms varies according to the ground tracks approaching or receding land. When a ground track passes from ocean to land, flat terrain in coastal areas largely affects the reflected waveforms. By contrast, if a ground track moves over the undulating coastal terrain before approaching the ocean, the reflected waveforms are strongly contaminated because of fairly large lag effect of AGC and tracking-loop response. Therefore, focusing more on the accuracy of coastal retracked SSHs affected by the aforementioned factors is important for researchers, while coastal SSHs are used to study coastal ocean signals. The Taiwan Strait is naturally a shallow sea where ocean tides are complex and high, leading to inaccurate correction from tide models. As a consequence, the accuracy of retracked Envisat SSHs in this area is also comparatively low. Therefore, if more accurate ocean tide models are introduced in the future, the uncertainty in altimetry data is expected to reduce.

Acknowledgments. We acknowledge the support through the provision of grants from the National Science Council of Taiwan (MOST 101-2221-E-006-180-MY3; MOST 103-2221-E-006-115MY3) and the Headquarters of University Advancement at National Cheng Kung University. We are grateful as well for the European Space Agency for providing with the Envisat altimeter data products that are necessary for the project and for C.K. Shum, Hyongki Lee and Kuo-Hsin Tseng of the Ohio State University for their inputs on data processing. Lastly, we appreciate the assistance of the editor and the anonymous reviewers. The figures were prepared using the GMT graphics package (Wessel and Smith, EOS 1991).

\section{References}

Amante, C. and Eakins, B.W. (2009). ETOPO1 1 Arc-Minute Global Relief Model: Procedures, Data Sources and Analysis, NOAA Technical Memorandum NESDIS NGDC-24, National Geophysical Data Center, Boulder, Colorado, USA.

Bamber, J.L. (1994). Ice sheet altimeter processing scheme. Int. J. Remote Sens., 15(4), 925-938. http://dx.doi.org/10.1080/01431169 408954125

Brown, G.S. (1977). The average impulse response of a rough surface and its applications. IEEE Trans. Antennas Propagation, 25(1), 67-74. http://dx.doi.org/10.1109/TAP.1977.1141536

Chang, X.T., Li, J.C., Guo, J.Y., and Hwang, C. (2006). A multileading edge and multi-threshold waveform retracker. Chin. J. Geophys., 49(6), 1483-1489. http://dx.doi.org/10.1002/cjg2.975

CLS (1997). Algorithms Definition and Accuracy, Collecte Localisation Satellites, RA2/MWR LOP, CLS.OC/NT/96.038, Issue 2 rev 1, Nomenclature: PO-NT-RAA-0004-CLS.

COASTALT (2011). Envisat Coastal Altimetry Product Handbook, ESA: ENVI-DTEX-EOPS-TN-09-0006, Issue: 2.0.1.

Davis, C.H. (1997). A robust threshold retracking algorithm for measuring ice-sheet surface elevation change from satellite radar altimeters. IEEE Trans. Geosci. Remote Sens., 35(4), 974-979. http://dx.doi.org/10.1109/36.602540

Deng, X., Featherstone, W.E., Hwang, C., and Berry, P.A.M. (2002). Estimation of contamination of ERS-2 and Poseidon satellite radar altimetry close to the coasts of Australia. Mar. Geodesy, 25(4), 249-271. http://dx.doi.org/10.1080/01490410214990

Deng, X., and Featherstone, W.E. (2006). A coastal retracking system for satellite radar altimeter waveforms: Application to ERS - 2 
around Australia. J. Geophys. Res. (C Oceans), 111(C6), 19782012. http://dx.doi.org/10.1029/2005JC003039

Franco, A.S. (1988). Tides: Fundamentals, Analysis and Prediction, 2nd Ed., Fundação Centro Tecnológico de Hidráulica, São Paulo, Brazil.

Gommenginger, C., Thibaut, P., Fenoglio-Marc, L., Quartly, G., Deng, X., Gómez-Enri, J., Challenor, P., and Gao, Y. (2009). Retracking altimeter waveforms near the coasts, in S. Vignudelli, A. Kostianoy, and P. Cipollini (Eds.), Coastal Altimetry, Springer Berlin Heidelberg, pp. 61-101.

Gommenginger, C., Thibaut, P., and Fenoglio-Marc, L. (2011). Retracking, altimeter waveforms near the coasts: A review of retracking methods and some applications to coastal waveforms, in S. Vignudelli, A. Kostianoy, and P. Cipollini (Eds.), Coastal Altimetry, Springer Berlin Heidelberg.

Goshtasby, A. and O'Neill, W.D. (1994). Curve fitting by a sum of Gaussians, CVGIP: Graphical Models Image Process., 56(4), 281-288. http://dx.doi.org/10.1006/cgip.1994.1025

Halimi, A., Mailhes, C., Tourneret, J.Y., Thibaut, P., and Boy, F. (2013). Parameter estimation for peaky altimetric waveforms IEEE Trans. Geosci. Remote Sens., 51(3), 1568-1577. http://dx.doi. org/10.1109/TGRS.2012.2205697

Hwang, C., Guo, J., Deng, X., Hsu, H.Y., and Liu, Y. (2006). Coastal gravity anomalies from retracked Geosat/GM altimetry: Improvement, limitation and the role of airborne gravity data. J. Geodesy, 80(4), 204-216. http://dx.doi.org/10.1007/s00190-006-0052-x

Idris, N.H. and Deng, X. (2012). The retracking technique on multi-peak and quasi-specular waveforms for Jason-1 and Jason-2 missions near the coast. Mar. Geodesy, 35(S1), 217-237. http://dx doi.org/10.1080/01490419.2012.718679

Kuo, C.Y. (2006). Determination and Characterization of 20th Century Global Sea Level Rise, OSU-Report No 478, Geodetic Science Program, The Ohio State University, Columbus, Ohio, USA.

Kuo, C.Y., Kao, H.C., Lee, H., Cheng, K.C., and Lin, L.C. (2012). Assessment of radar waveform retracked Jason-2 altimetry sea surface heights near Taiwan coastal ocean. Mar. Geodesy, 35(2), 188-197. http://dx.doi.org/10.1080/01490419.2011.637861

Lee, H., Shum, C.K., Yi, Y., Braun, A., and Kuo, C.Y. (2008). Laurentia crustal motion observed using TOPEX/POSEIDON radar altimetry over land. J. Geodynamics, 46(3-5), 182-193. http://dx.doi.org/10.1016/j.jog.2008.05.001

Lee, H., Shum, C.K., Emery, W., Calmant, S., Deng, X., Kuo, C.Y., Roesler, C., and Yi, Y. (2010). Validation of Jason-2 altimeter data by waveform retracking over California coastal ocean. Mar. Geodesy, 33(S1), 304-316. http://dx.doi.org/10.1080/01490419.20 10.488982
Matsumoto, K., Takanezawa, T., and Ooe, M. (2000). Ocean tide models developed by assimilating TOPEX/POSEIDON altimeter data into hydrodynamical model: A global model and a regional model around Japan. J. Oceanogr., 56(5), 567-581. http://dx.doi. org/10.1023/A:1011157212596

Nicholls, R.J. and Leatherman, S.P. (1994). Global sea-level rise, in K. Strzepek and J.B. Smith (Eds.), As Climate Changes: Potential Impacts and Implications, Cambridge University Press, Cambridge.

Nicholls, R.J. (2011). Planning for the impacts of sea level rise. Oceanography, 24(2), 144-157. http://dx.doi.org/10.5670/oceanog. 2011.34

Pavlis, N.K., Holmes, S.A., Kenyon, S.C., and Factor, J.K. (2012). The development and evaluation of the Earth Gravitational Model 2008 (EGM2008). J. Geophys. Res. (B Solid Earth) (1978-2012), 117(B04406). http://dx.doi.org/10.1029/2011JB008916

Rahmani, M.A., and Zarghami, M. (2015). The use of statistical weather generator, hybrid data driven and system dynamics models for water resources management under climate change. $J$. Environ. Inf., 25(1), 23-35. http://dx.doi.org/10.3808/jei.201400 285

Remy, F., Brossier, C., and Minster, J.F. (1990). Intensity of satellite radar-altimeter return power over continental ice: A potential measurement of katabatic wind intensity. J. Glaciol., 36(123), 133-142.

Smith, W.H.F. and Scharroo, R. (2015). Waveform aliasing in satellite radar altimetry. IEEE Trans. Geosci. Remote Sens., 53(4), 1671-1682. http://dx.doi.org/10.1109/TGRS.2014.2331193

Tseng, K.H., Shum, C.K., Yi, Y., Emery, W.J., Kuo, C.Y., Lee, H., and Wang, H. (2014). The improved retrieval of coastal sea surface heights by retracking modified radar altimetry waveforms. IEEE Trans. Geosci. Remote Sens., 52(2), 991-1001. http://dx.doi.org/10. 1109/ TGRS.2013.2246572

Vignudelli, S., Kostianoy, A.G., Cipollini, P., and Benveniste, J. (2011). Coastal Altimetry, Springer-Verlag Berlin Heidelberg. http://dx.doi.org/10.1007/978-3-642-12796-0

Willis, J.K., Chambers, D.P., Kuo, C.Y., and Shum, C.K. (2010). Global sea level rise: Recent progress and challenges for the decade to come. Oceanography, 23(4), 26-35. http://dx.doi.org/10. 5670 /oceanog. 2010.03

Xia, X.H., Wu, Q., Mou, X.L., and Lai, Y.J. (2015). Potential impacts of climate change on the water quality of different water bodies. $J$. Environ. Inf., 25(2), 85-98. http://dx.doi.org/10.3808/jei.2014002 63 